\title{
EL ACUÍFERO GUARANÍ EN BRASIL Y SU PROTECCIÓN POR MEDIO DE LA LEGISLACIÓN AMBIENTAL Y URBANÍSTICA: UN ESTUDIO DE CASO ${ }^{1}$
}

\author{
Luciana Cordeiro de Souza-Fernandes \\ Profesora de Derecho. Universidad Estadual de Campinas (UNICAMP) \\ luciana.fernandes@fca.unicamp.br
}

Recibido: 24 de septiembre de 2014 / Aceptado: 7 de abril de 2015

RESUMEN: El Sistema Acuífero Guaraní (SAG) es una de las fuentes de aguas subterráneas más importantes de América Latina y abarca un área que comprende partes del territorio de cuatro países: Argentina, Brasil, Paraguay y Uruguay. Su mayor parte se halla en territorio brasileño, en ocho estados: Goiás, Mato Grosso, Mato Grosso do Sul, Minas Gerais, São Paulo, Paraná, Santa Catarina y Rio Grande do Sul. En la cartografía del SAG en el estado de São Paulo se han identificado sus zonas de afloramiento y se han propuesto medidas técnicas y legales para su protección, debido a la interacción entre las aguas subterráneas y las aguas superficiales y sus áreas de recarga. Ello ha llevado a su declaración como áreas vulnerables. En Brasil, es el Estado quién legisla sobre las aguas subterráneas, y los municipios en el uso y manejo del suelo. Por lo tanto, el municipio de Araraquara, en el estado de São Paulo, fue innovador al legislar instituyendo la Zona de Protección del Acuífero Regional y estableciendo las directrices de uso y ocupación del suelo en parte del área de afloramiento en su territorio para protección del SAG. Esta iniciativa legal unió instrumentos del derecho ambiental con instrumentos del derecho urbanístico para promover la protección de la calidad de las aguas subterráneas.

RESUM: El Sistema Aqüífer Guaraní (SAG) és una de les fonts d'aigües subterrànies més importants d'Amèrica Llatina $\mathrm{i}$ abasta un àrea que compren parts del territori de quatre països: Argentina, Brasil, Paraguai i Uruguai. La seva major part es troba en

\footnotetext{
${ }^{1}$ Proyecto de investigación FAPESP núm. 2013/10689-6.
} 
territori brasiler, en vuit estats: Goiàs, Mato Grosso do Sul, Minas Gerais, São Paulo, Paraná, Santa Catarina i Rio Grande do Sul. A la cartografia del SAG a l'estat de São Paulo s'han identificat les seves zones d'aflorament i s'han proposat mesures tècniques i legals per a la seva protecció, com a conseqüència de la interacció entre les aigües subterrànies i les aigües superficials i les àrees de recàrrega. Això ha dut a la seva declaració com a àrees vulnerables. Al Brasil, l'estat legisla sobre les aigües subterrànies i els municipis sobre l'ús i maneig del sòl. Per tant, el municipi d'Araraquara, a l'estat de São Paulo, va ser innovador en legislar tot instituint la Zona de Protecció de l'Aqüífer Regional i establint les directrius d'ús i ocupació del sòl en part de l'àrea d'aflorament en el seu territori per a la protecció del SAG. Aquesta iniciativa legal va unir instruments del dret ambiental amb instruments del dret urbanístic per promoure la protecció de la qualitat de les aigües subterrànies.

ABSTRACT: The Guarani Aquifer System (GAS) is an important groundwater source in Latin America and expands over an area that comprises parts of the territory of four countries: Argentina, Brazil, Paraguay and Uruguay. Its greatest portion is in Brazilian territory, covering eight states: Goiás, Mato Grosso, Mato Grosso do Sul, Minas Gerais, São Paulo, Paraná, Santa Catarina and Rio Grande do Sul. The SAG cartography identifies its upwelling zones in the state of São Paulo. Here, technical and legal protection measures were proposed, due to the complex interactions between groundwater and surface water that provide the base flow of rivers and lakes of the region. Eventually, this has led to defining these zones as vulnerable areas. In Brazil, states have the power to legislate over groundwater, whereas local governments do so over land use and land management. The Araraquara municipality, in the state of São Paulo, has enacted innovative legislation for the protection of the upwelling areas in its territory, establishing the Protection Zone for the Regional Aquifer, as well as directives for land use and management. This initiative has streamlined environmental law instruments with land planning instruments to ensure the protection and quality of groundwater.

PALABRAS CLAVE: Acuífero Guaraní - Plan Director de Araraquara - principio de prevención — sostenibilidad — derecho brasileño. 
PARAULES CLAU: Aqüífer Guaraní - Pla Director d'Araraquara - principi de prevenció — sostenibilitat — dret brasiler.

KEYWORDS: Guarani Aquifer System — Araraquara Environmental Planning — Principle of Prevention - Sustainability — Brazilian Law.

Sumario: I. Introducción. II. El medio ambiente en la Constitución Federal. 1. Consideraciones preliminares. 2. Competencia constitucional. 2.1. Competencia constitucional para el agua. 2.2. Competencia constitucional para el uso y la ordenación del suelo. III. Breves notas de la legislación de recursos hídricos y aspectos de la polución. IV. El Sistema Acuífero Guaraní (SAG). V. Las zonas de afloramiento del Sistema Acuífero Guaraní en el estado de São Paulo. VI. El Plan Director AraraquaraSão Paulo. 1. Anterior Plan Director de Araraquara. 2. La Ley Complementaria 49/01. 3. Actual Plan Director de Araraquara-São Paulo. VII. Conclusiones. VIII. Bibliografía.

\section{INTRODUCCIÓN}

En Brasil, el marco jurídico ambiental y urbanístico en vigor ofrece varias herramientas para la protección de los recursos naturales, lo que, junto con los conocimientos técnicos, constituye un todo armónico en la ejecución de las medidas técnicas para la preservación, conservación y protección del medio ambiente para las generaciones presentes y futuras, de acuerdo con la Constitución Federal brasileña.

Siendo así, al estudiar el Sistema Acuífero Guaraní (SAG), importante manantial subterráneo de América Latina, enfocamos nuestro análisis en su área de afloramiento por ser un área de vulnerabilidad del SAG, más precisamente en el municipio de Araraquara, en el Estado de São Paulo. Presentaremos las herramientas legales que se utilizaron en la del Plan Director y en la ley complementaria núm. 49/01 para ofrecer protección a una parte de esta área del Acuífero Guaraní en este territorio.

En Brasil es responsabilidad de los estados legislar sobre aguas subterráneas y a los municipios les cabe legislar sobre el uso y ordenamiento del suelo, no existiendo en la práctica una integración efectiva en el modo de legislar en los municipios, las leyes del uso del suelo no se ocupan de las aguas subterráneas. Dado que la contaminación de las aguas subterráneas se pasa a través del suelo, la clave para la protección de las aguas subterráneas es una gestión integrada entre el suelo y el agua, con utilización de instrumentos del derecho ambiental y urbanístico conjuntamente. 
De esta forma, creemos que la garantía de la efectividad de la legislación municipal en estudio, que innovó en el sistema legal brasileño al legislar específicamente el uso del suelo para via reflexiva proteger el Acuífero Guaraní, podrá servir de paradigma para otros tantos municipios que se sirven de las aguas subterráneas, como lo hace el municipio de Araraquara-SP.

\section{EL MEDIO AMBIENTE EN LA CONSTITUCIÓN FEDERAL}

\section{Consideraciones preliminares}

La legislación ambiental brasileña es bastante avanzada y dispone de un verdadero arsenal legislativo aplicable al objetivo de este estudio, sea directa o indirectamente, y la Constitución Federal es el punto de partida para nuestro trabajo.

Conviene notar que el Texto Constitucional, de 5 de noviembre de 1988, en el artículo 225, dio la bienvenida a la llamada Ley de la Política Nacional del Medio Ambiente Ley Federal núm. 6.938, de 31 de agosto de 1981, cuyo objetivo es la preservación, mejora y restauración de la calidad del medio ambiente propicia para la vida, para garantizar, en el país, las condiciones para el desarrollo socioeconómico, los intereses de la seguridad nacional y la protección de la dignidad de la vida humana. Especial atención debe darse al hecho de que en 1988 la Constitución afirmó que el medio ambiente es un bien de uso común del pueblo brasileño, es decir, a partir de ese momento, todos los elementos que componen el medio ambiente empiezan a ser parte de la naturaleza jurídica de bien difuso, o sea, no es un bien público o un bien privado, sino un bien ambiental. En una traducción libre, presentamos el artículo 225 de la Constitución brasileña:

Art. 225. Todos tienen derecho a un medio ambiente ecológicamente equilibrado, bien de uso común y esencial para una calidad de vida saludable, que impone al Gobierno y a la colectividad el deber de defenderlo y preservarlo para las presentes y generaciones futuras.

$\S 1$ Para asegurar la efectividad de este derecho recae en el Gobierno:

I - preservar y restaurar los procesos ecológicos esenciales y proporcionar el manejo ecológico de las especies y los ecosistemas; 
II - preservar la diversidad y la integridad del patrimonio genético del País y fiscalizar las entidades dedicadas a la investigación y manipulación de material genético;

III - definir, en todas las unidades de la Federación, espacios territoriales y sus componentes para ser especialmente protegidos, y la alteración y supresión solo permitidas a través de la ley, prohíbe cualquier uso que comprometa la integridad de los atributos que justifican su protección;

IV - requerir, de acuerdo con la ley, para la instalación de la obra o actividad potencialmente causadora de una degradación significativa del medio ambiente, estudio previo de impacto ambiental, que se hará público;

$\mathrm{V}$ - controlar la producción, la comercialización y el uso de técnicas, métodos y sustancias que representan un riesgo para la vida, la calidad de vida y el medio ambiente;

VI - promover la educación ambiental en todos los niveles de educación y conciencia pública para la preservación del medio ambiente;

VII - proteger la fauna y la flora, prohibiéndose, de acuerdo con la ley, las prácticas que ponen en peligro su función ecológica, causan la extinción de especies o maltratan animales.

\section{Competencia constitucional}

De acuerdo con José Afonso DA SILVA², las competencias son las distintas formas de poder que sirven a los organismos o entidades del Estado para llevar a cabo sus funciones.

El autor aclara que la Constitución Federal brasileña, a causa de la autonomía de sus entes federativos -Unión, estados y municipios-, permitió hablar de especies de competencia en medio ambiente, visto que las materias que componen su contenido pueden ser agrupadas en clases, según su naturaleza, su vinculación acumulativa a más de una entidad y su vínculo a la función del gobierno. Bajo estos criterios, podemos identificar dos grandes grupos de competencias, con sus subclases:

\footnotetext{
${ }^{2}$ DA SILVA, José Afonso, Curso de Direito Constitucional Positivo, Malheiros Editores, São Paulo, 1999, p. 419.
} 
I. Competencia material, que puede ser: a) exclusiva (art. 21); y b) común, acumulativa o paralela (art. 23);

II. Competencia legislativa, que puede ser: a) exclusiva (art. 25 , $\S 1$ y 2 ; b) privativa (art. 22); c) concurrente (art. 24); y d) suplementaria (art. 24, $\S 2^{\circ}$ ).

Celso FIORILLO ${ }^{3}$ aclara estas calificaciones de competencias:

I. Competencia material:

a) Exclusiva (art. 21): atribuida a una entidad con exclusión de las demás.

b) Común, acumulativa o paralela (art. 23): consiste en un campo de actuación común a las diversas entidades, sin que el ejercicio de una venga a excluir la competencia de otra, que puede así ser ejercida acumulativamente. Significa la posibilidad de practicar algunos actos, en determinadas esferas de competencia de forma conjunta y en pie de igualdad.

II. Competencia legislativa:

a) Exclusiva (art. 25, $\S \S 1^{\circ}$ y $2^{\circ}$ ); atribuida a una entidad con exclusión de los demás.

b) Privativa (art. 22); enumerada como propia de una entidad, con posibilidad, sin embargo, de delegación y competencia complementaria (art. 22 y su párrafo único). Difiere de la exclusiva en la medida en que esta es indelegable.

c) Concurrente (art. 24); concepto que comprende dos elementos, a saber, posibilidad de disposición sobre el mismo asunto o materia por más de una entidad federativa, así como primacía de la Unión en lo que respecta a las normas generales.

d) Suplementaria (art. 24, $\S 2^{\circ}$ ); vinculada a la competencia concurrente, significa el poder para suplir las lagunas en la ley.

\subsection{Competencia constitucional para el agua}

De este modo, la Constitución se ocupó de la jurisdicción sobre las aguas en diferentes dispositivos, lo que permite diferentes interpretaciones del tema. Primeramente, el legislador atribuye a la Unión competencia privativa:

Art. 22. Compite privativamente a la unión legislar sobre:

\footnotetext{
${ }^{3}$ FIORILlo, Celso Antonio Pacheco, O Direito de Antena em face do Direito Ambiental no Brasil, Saraiva, São Paulo, 2000, p. 79.
} 
$[\ldots]$

IV - aguas, informática, telecomunicaciones y radiodifusión (grifo nosso)

La expresión aguas fue empleada de forma genérica, lo que permite, por lo tanto, una interpretación variada. Paulo Affonso LEME MACHADO ${ }^{4}$ señala lo siguiente:

[...] legislar sobre aguas significa instituir normas sobre la calidad y la cantidad de aguas y establecer reglas de cómo las aguas serán tratadas, compartidas y utilizadas. No se comprendería que la Constitución hiciese referencia a las aguas solamente como un elemento de la naturaleza que debiese quedar en los ríos y lagos. Hay un gran alcance del poder normativo de la Unión, que debe ser utilizado para que las legislaciones estatales no creen normas discriminatorias o que estimulen políticas distintas y hasta antagónicas sobre el uso de las aguas.

Según José Afonso DA SILVA ${ }^{5}$ :

[L]a legislación de dos estados sobre aguas depende, sin embargo, de lo que disponga la ley federal, a la cual cabe definir las normas de calidad de las aguas y los criterios de clasificación de las aguas de los ríos, lagos etc. Los estados no pueden pues establecer condiciones distintas para cada clase de agua ni tampoco innovar la clasificación ni los criterios de uso.

En el mismo artículo 22 de la Constitución Federal, en su párrafo único, se prevé la posibilidad de dictar ley complementaria que autorice a los estados a legislar sobre aguas.

En el artículo 23, sección VI, la Constitución establece que la Unión, el Distrito Federal, los estados y los municipios tienen la competencia para proteger el medio ambiente y luchar contra la contaminación en cualquiera de sus formas.

Más adelante, al enumerar las competencias concurrentes de la Unión, los estados y el Distrito Federal, el legislador les atribuye, en el artículo 24, sección VI, la competencia para legislar sobre el medio ambiente, siendo el agua un recurso natural, tal como se indica al inicio de este apartado.

\footnotetext{
${ }^{4}$ MACHADO, Paulo Affonso Leme, Recursos Hídricos. Direito Brasileiro e Internacional, Malheiros Editores, São Paulo, 2002, p. 19.

5 DA SILVA, José Afonso, Curso de Direito Constitucional Positivo, Malheiros Editores, São Paulo, 1999 , p. 87.
} 
En este mismo artículo, en su sección VIII, se determinó la competencia concurrente de la Unión, los estados y el Distrito Federal para legislar sobre la responsabilidad por daño al medio ambiente, lo que engloba aspectos de contaminación del agua.

Extrajimos entonces que la Constitución fue centralizadora en la competencia para legislar sobre el agua, y común para que los entes de la Federación legislen sobre la protección del medio ambiente.

Sin embargo, son los estados que tienen la competencia para legislar en materia de aguas subterráneas (art. 26, sección I, de la Constitución Federal), pero la gran mayoría de los estados solo cuenta con leyes, decretos, reglamentos y ordenanzas para el uso de las aguas superficiales. Solo diez estados tienen legislación específica sobre las aguas subterráneas, lo que denota la gran indiferencia legislativa sobre el tema y el peligro aún mayor de la contaminación de nuestras fuentes de agua subterránea por el uso inadecuado del suelo.

En este escenario, el estado de São Paulo destaca como el primer estado del país a legislar sobre sus aguas subterráneas, demostrando la preocupación constante tanto de los técnicos como de los legisladores con respecto a las aguas subterráneas. Este hecho se pone de manifiesto por la sanción de la Ley núm. 6.134, de 2 de junio de 1988, reglamentada por el Decreto núm. 32.955, de 7 de febrero de 1991, que trata específicamente sobre las aguas subterráneas, proporcionando instrumentos técnicos para la ejecución de una política estadual sobre las aguas subterráneas. A ello se suma la Ley núm. 7.663, de 30 de diciembre de 1991, que estableció la Política Estadual sobre Recursos Hídricos del Estado de São Paulo, cuyos artículos 9 al 13 legislan sobre la concesión de derechos de uso de los recursos de aguas subterráneas. Esta ley fue reglamentada por el Decreto núm. 41.258, de 31 de octubre de 1996, que regula su aplicación.

\subsection{Competencia constitucional para el uso y la ordenación del suelo}

En conformidad con los artículos 1 y 18 de la Constitución Federal, la entidad federativa municipio recibió autonomía, con competencias exclusivas como de la ordenación del suelo entre otras (art. 30) y de la organización política propia (art. 29), que se manifiesta en la forma de proteger el medio ambiente y los recursos naturales. 
La competencia legislativa en cuanto al uso y la ordenación del suelo es conferida a los municipios, de acuerdo con el artículo 30, sección VIII, a quienes corresponde "promover, en lo que quepa, el adecuado ordenamiento territorial, mediante planeamiento y control del uso, de la división y la ocupación del suelo urbano", así como legislar sobre asuntos de interés local (sección I). O sea, el municipio puede y debe participar en la gestión de las aguas subterráneas. Y esto se da por medio de la ley del Plan Director que tiene como suyos instrumentos de planificación de suelo.

La Ley Federal núm. 10.257, de 10 de julio de 2001, regula los artículos 182 y 183 de la Constitución Federal, establece las directrices generales para la política urbana, instituyendo el llamado Estatuto de la Ciudad, que ofrece diversos instrumentos urbanísticos para la gestión de las ciudades, entre ellos el Plan Director.

El Plan Director es un plan general e integral que constituye el instrumento de los municipios para sistematizar el desarrollo físico, económico y social del territorio municipal, buscando el bienestar de la comunidad local. Es un plan porque establece objetivos a alcanzar, el plazo en que estos objetivos deben alcanzarse, las actividades a realizar y quién deberá realizarlas. Es director porque fija las pautas de desarrollo urbano del municipio ${ }^{6}$. El Plan Director, creado de manera participativa con la sociedad, se instrumentaliza mediante una ley municipal aprobada en el Concejo Municipal (Legislativo), con la realización de audiencias públicas de la comunidad de la ciudad, para su sanción por parte del Ejecutivo.

La zonificación es una herramienta dentro del Plan Director, puesto que es el conjunto de normas legales que configuran el derecho de propiedad y el derecho de construir, de acuerdo con el principio de función social de la ciudad y de la propiedad. Solamente por medio de una ordenación adecuada del suelo del municipio se cumplirá la función social de la propiedad, pues en la zonificación del suelo que se establece la forma de usar y ocupar el suelo con vistas a la protección de los bienes ambientales en su totalidad, comprendidos en esto, los acuíferos.

El Estatuto de la Ciudad integra los aspectos urbanísticos y ambientales como directrices para la elaboración del Plan Director municipal. Y en su artículo $2^{\circ}$, sección VI, $g$, hay previsión específica de "ordenación y control del uso del suelo, a fin de evitar: g) la polución y degradación ambiental". Sin embargo, la mayoría de los

\footnotetext{
${ }^{6}$ DA SILVA, José Afonso, Direito urbanistico brasileiro, Malheiros, São Paulo, 1992, p. 216.
} 
municipios brasileños, al legislar la ordenación del uso del suelo, no consideran los atributos ambientales en el planeamiento del suelo urbano, menos aún de los acuíferos, que no son tenidos en cuenta.

Solo a través del ordenamiento adecuado de los suelos de la provincia se cumple la función social de la propiedad, considerada como un derecho fundamental (art. $5^{\circ}$, sección XXIII) y principio básico de la orden económica brasileña (art. 170, sección III) de la Constitución Federal. Y a través de la zonificación territorial que ocurrirá los permisivos para el uso y ocupación del suelo con el fin de proteger los bienes ambientales en su totalidad, comprendidos los acuíferos. La zonificación es una de las herramientas capaces de dar relevancia al principio ambiental de precaución.

Sobre eso, tenemos que las funciones sociales de la ciudad necesitan de la zonificación ambiental como instrumento vinculado para asegurar el bienestar a los habitantes de un determinado municipio, lo que significa afirmar la necesidad de la creación de los llamados espacios ambientales (partes del territorio establecidas con el propósito de proteger y preservar el medio ambiente), con la zonificación de uso ambiental y urbanística.

De esta forma, a partir del conocimiento técnico sobre los acuíferos, entendemos que la adopción de medidas restrictivas de uso del suelo es la forma más eficaz para protegerlos.

Así, el derecho de propiedad sufrirá restricciones, pues "el suelo es el elemento clave para la protección de los acuíferos, será a modo de ordenar el uso y ocupación de el suelo en la faz de la Tierra, que aseguraremos el beneficio del uso de las aguas subterráneas" 7 .

\section{BREVES NOTAS DE LA LEGISLACIÓN FEDERAL DE RECURSOS HÍDRICOS Y ASPECTOS DE LA POLUCIÓN}

La Política Nacional de Recursos Hídricos - Ley núm. 9.433, de 8 de enero de 1997, aunque no hace mención de los recursos de agua subterránea, plantea, en su artículo $5^{\circ}$, cinco herramientas para la realización de esta política:

\footnotetext{
${ }^{7}$ CORDEIRO DE SOUZA, Luciana, Águas subterrâneas e a Legislação brasileira, Juruá, Curitiba, 2009, p. 184.
} 
Art. 5. Son instrumentos de la Política Nacional de Recursos Hídricos:

I - los planes de los Recursos Hídricos;

II - la clasificación de los cuerpos de agua en clases, de acuerdo con los usos predominantes de agua;

III - la concesión de derechos de uso de los recursos hídricos;

IV - el cobro por el uso de los recursos hídricos;

$\mathrm{V}$ - (Inexistente)

VI - el Sistema de Información de Recursos Hídricos.

En la práctica, los planes de recursos hídricos, comúnmente traducidos como planes de cuencas, evalúan la disponibilidad hídrica subterránea de acuerdo con los análisis y las orientaciones de órganos gestores, porque, conceptualmente, siendo el agua subterránea un componente inseparable del ciclo hidrológico, su disponibilidad en el acuífero está directamente relacionada con el flujo básico de la cuenca de drenaje instalada en el área de ocurrencia. Las aguas subterráneas constituyen una parte de ese flujo que, a su vez, es una recarga transitoria del acuífero.

Esta cuestión es importante no solo para establecer el potencial de agua, sino también para el control de las fuentes de contaminación de cada cuenca.

Hacemos hincapié en que el artículo 3. ${ }^{\circ}$, sección III, de la Ley de la Política Nacional Ambiental - Ley núm. 6938/81, define la contaminación como:

Art. 3. A los efectos previstos en esta Ley, se aplicarán las siguientes definiciones:

III - la contaminación, la degradación de la calidad del medio ambiente como resultado de las actividades que directa o indirectamente:

a) dañan la salud, la seguridad y el bienestar de la población;

b) crean condiciones adversas para las actividades sociales y económicas;

c) afectan negativamente a la biota;

d) afectan a las condiciones estéticas o sanitarias del medio ambiente;

e) lanzan materias orgánicas contraviniendo las normas ambientales establecidas.

De aquí podemos inferir que hay diversas actividades humanas que pueden causar la contaminación del medio ambiente, sea directa o indirectamente, y, por lo tanto, 
debemos implementar herramientas tanto para evitarlas como para mitigar sus impactos, especialmente en las aguas subterráneas.

El Plan Nacional de Recursos Hídricos del Ministerio de Medio Ambiente afirma, sobre la vulnerabilidad de nuestros acuíferos, lo siguiente:

Los recursos hídricos subterráneos en Brasil están sujetos a una serie de riesgos, entre ellos es importante citar: la contaminación de las aguas subterráneas por los efluentes domésticos e industriales, pesticidas, fertilizantes, sustancias tóxicas de los vertidos, por ejemplo, de tanques de combustible. La gravedad de la contaminación se relaciona con la toxicidad, la persistencia, la cantidad y concentración de las sustancias que llegan a las fuentes subterráneas ${ }^{8}$.

El Gobierno del estado de São Paulo, a través del Departamento de Agua y Energía (DAEE), también explica cómo se produce la contaminación de los acuíferos:

Se produce cuando los contaminantes llegan al suelo que puede absorberlos como una esponja; sin embargo, a menudo estos contaminantes llegan a las aguas subterráneas. La contaminación de las aguas subterráneas puede ocurrir por dos vías distintas: una por el transporte de contaminantes por las aguas de lluvia que se infiltran rápidamente hasta llegar a los niveles de agua subterránea; o cuando los contaminantes han alcanzado el acuífero y se mueven lateralmente ${ }^{9}$.

Por lo tanto, la legislación ambiental y sus instrumentos de protección deben estar asociados con la legislación urbanística, ya que la vida sucede en las ciudades, y este espacio territorial que disfrutamos de la calidad de vida, así como todas las medidas técnicas y legales deben ser tomados con ese propósito. No se puede disociar la protección ambiental del ordenamiento territorial y el uso del suelo.

Así, desde el conocimiento técnico de los acuíferos, creemos que la adopción de medidas restrictivas en el uso del suelo es la forma más eficaz de proteger los acuíferos y que el Plan Director de los municipios puede contemplar tales medidas.

\footnotetext{
8 MINISTÉRIO DO MEIO AMBIENTE, Águas subterrâneas: programa de águas subterrâneas, Ministério do Meio Ambiente, Brasília, 2001, p. 10.

${ }^{9}$ GOUVÊA DA SILVA, Rosa Beatriz, Águas Subterrâneas: Um valioso recurso que requer proteção, DAEE, São Paulo, 2003, p. 16.
} 


\section{EL SISTEMA ACUÍFERO GUARANÍ (SAG)}

El Acuífero Guaraní tiene una reserva de agua subterránea que se extiende por Brasil, Paraguay, Uruguay y Argentina lo que equivale a los territorios de Reino Unido, Francia y España juntos. En Brasil, se extiende por los estados de Goiás, Mato Grosso do Sul, Minas Gerais, São Paulo, Paraná, Santa Catarina y Rio Grande do Sul.

La figura 1 abajo presenta una proyección del Acuífero Guaraní en los territorios de Brasil, Paraguay, Argentina y Uruguay.

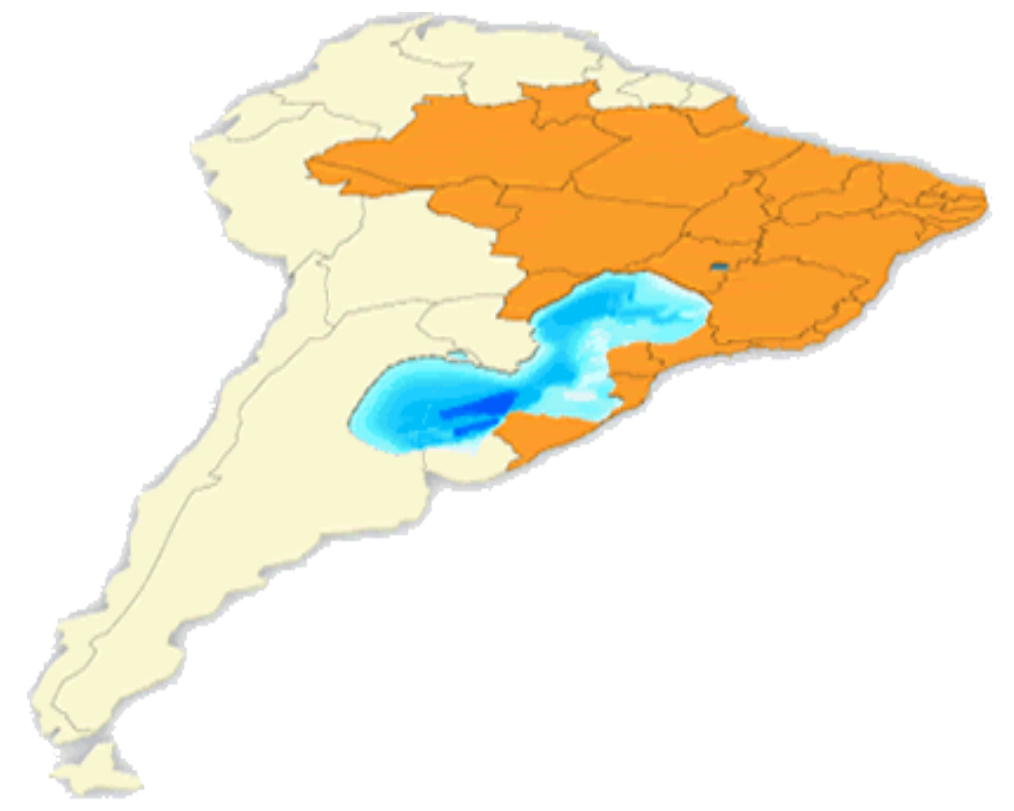

Figura 1- Ubicación aproximada del Acuífero Guaraní en América del Sur.

(Fuente: Unidad Nacional de Preparación del Proyecto Acuífero Guaraní - UNPP/Brasil, 2000)

La área de ocurrencia del Acuífero Guaraní es de $1.195 .200 \mathrm{~km}^{2}$, y extrapola la parte brasileña de la Cuenca del Paraná (Brasil y Paraguay), con más de $839.800 \mathrm{~km}^{2}$ (distribuidos en el subterráneo de ocho estados brasileños de la siguiente manera: MS = $213.200 \mathrm{~km}^{2} ; \mathrm{RS}=157.600 \mathrm{~km}^{2} ; \mathrm{SP}=155.800 \mathrm{~km}^{2} ; \mathrm{PR}=131.300 \mathrm{~km}^{2} ; \mathrm{GO}=55.000$ $\mathrm{km}^{2} ; \mathrm{MG}=51.300 \mathrm{~km}^{2} ; \mathrm{SC}=49.200 \mathrm{~km}^{2} ; \mathrm{y} \mathrm{MT}=26.400 \mathrm{~km}^{2}$ ), y se extiende en la dirección de Paraguay (71.700 km²), Argentina (225.300 km²) y Uruguay $\left(58.400 \mathrm{~km}^{2}\right)$. El acuífero está confinado por basaltos de la Formación Serra General (Cretáceo) y sedimentos del Pérmico-Triásico de baja permeabilidad. Las reservas de agua subterránea en la parte brasileña de este Sistema Acuífero se estiman en $48.000 \mathrm{~km}^{3}$, siendo la recarga natural en $118.000 \mathrm{~km}^{2}$ de afloramiento en torno a los $26 \mathrm{~km}^{3} / \mathrm{año}$, 
mientras que la recarga indirecta inducida por los potenciales hidráulicos superiores de las aguas acumuladas en los basaltos y sedimentos del Grupo Bauru/Caiuá, alrededor de $140 \mathrm{~km}^{3} /$ año, es decir, un total de $166 \mathrm{~km}^{3} / \mathrm{año}^{10}$.

Las aguas son de excelente calidad para consumo doméstico, industrial y de irrigación, $\mathrm{y}$, dado que las temperaturas son superiores a $30^{\circ} \mathrm{C}$ en toda área confinada, han sido ampliamente utilizadas para el desarrollo de centros turísticos. En alrededor del 70\% de la superficie de ocurrencia, donde las dimensiones topográficas son inferiores a los 500 metros, existe la posibilidad de que los pozos de aguas con artesianismo. La extracción de sus aguas es dominante y el desperdicio es flagrante, lo que exige medidas urgentes en los planes nacional e internacional ${ }^{11}$.

El Acuífero Guaraní es una fuente estratégica debido a sus características hidrogeológicas, extensión y ubicación pues se halla cerca de regiones de gran importancia socioeconómica para los cuatro países.

En São Paulo, el SAG es el mayor reservorio de agua subterránea, siendo una importante fuente de suministro de agua pública. Esto se debe a que sus aguas tienen una potabilidad generalmente bastante adecuada, estando clasificadas como bicarbonatadas sódicas y cálcico-magnesianas cerca de la zona de recarga directa ${ }^{12}$. Alrededor del $80 \%$ de los municipios paulistas se proveen, aunque sea parcialmente, de las aguas subterráneas. ${ }^{13}$

Sin embargo, las aguas del SAG, incluso estando cubiertos por una capa de basalto, no están libres de contaminación, ya que este tiene muchas zonas vulnerables, denominadas zonas de recarga y descarga.

Siendo que en el SAG tenemos también las zonas de afloramiento como puntos de recarga, que se refieren a la roca basáltica que cubre el acuífero y que aflora haciendo

\footnotetext{
${ }^{10}$ ALBUQUERQUE ROCHA, Gerôncio, "O grande manancial do Cone Sul”, Estudos Avançados, USP, vol. 11, núm. 30, 1997, p. 193.

${ }^{11}$ Ibid., p. 194.

${ }^{12}$ ASSINE, Mario Luis et ál. "Os paleodesertos Pirambóia e Botucatu”, Mantesso Neto, V., Bartorelli, A., Carneiro, C. D. R. y Brito-Neves, B. B. (orgs.), Geologia do Continente Sul-Americano: Evolução da obra de Fernando Flávio Marques de Almeida, Editora Beca, São Paulo, 2004, pp. 77-93.

13 CETESB. (2014, 15 de mayo) Águas. Recuperado el 15 de abril de 2014, de $<$ http://www.cetesb.sp.gov.br/>.
} 
un borde con el suelo, lo que hace vulnerable esta región fronteriza entre la roca y el suelo, que son áreas donde el basalto se encuentra con el suelo.

La figura 2 abajo destaca en verde oscuro el área de afloramiento del Acuífero Guaraní, considerada área vulnerable.

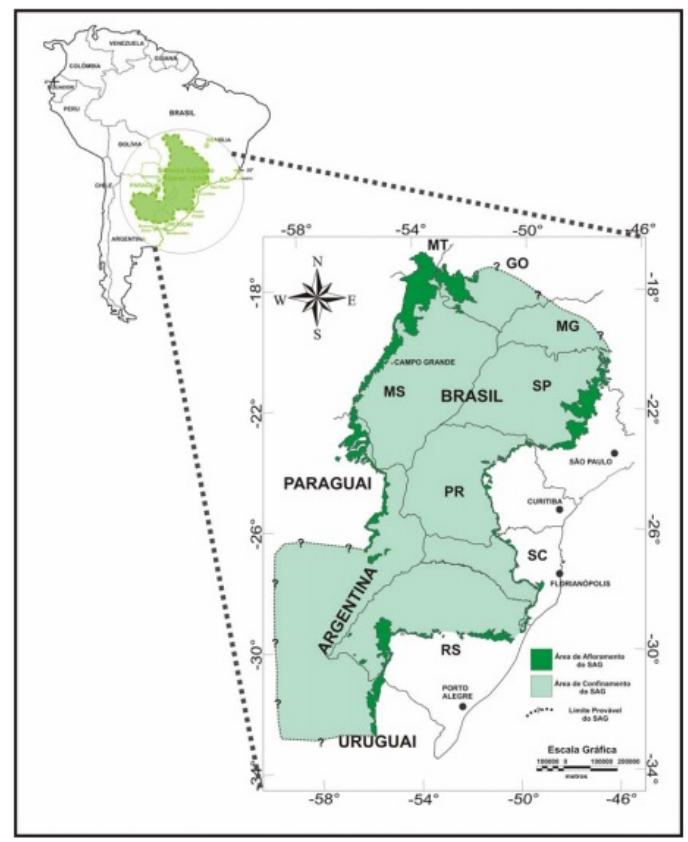

Figura 2. Ubicación del Sistema Acuífero Guaraní

(Fuente: GASTMANS, D.; 2007)

Las zonas de recarga son puntos del suelo, con una conexión directa con el acuífero, por donde las aguas de las lluvias recargan el acuífero; las áreas de descarga representan los puntos en que las aguas del acuífero emergen. La figura 3 presenta el esquema de las aguas subterráneas y sus áreas vulnerables.

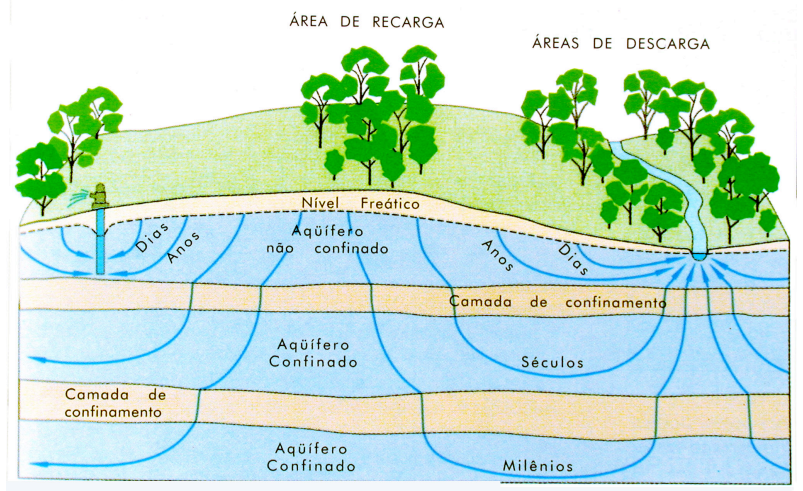

Figura 3. Áreas de recarga y descarga del acuífero

(Fuente: United States Geological Survay, Circular 1.139) 


\section{LAS ZONAS DE AFLORAMIENTO DEL SISTEMA ACUÍFERO GUARANÍ EN EL ESTADO DE SÃO PAULO}

El Sistema Acuífero Guaraní (SAG) es considerado una de las mayores reservas de agua dulce estratégicas en América Latina para el abastecimiento público y otros usos, por ser un reservorio aún sin explorar y ser relativamente más seguro que los recursos hídricos superficiales. En São Paulo ${ }^{14}$, el SAG es considerado la principal reserva de agua subterránea debido a sus propiedades hidrogeológicas e hidrogeoquímicas, con un área de presencia estimada en aproximadamente $143.000 \mathrm{~km}^{2}$. En el extremo oriental del estado se encuentra la parte de afloramiento, con aproximadamente $15.000 \mathrm{~km}^{2}, \mathrm{y}$, al oeste de esta parte, el sistema acuífero está confinado por las rocas basálticas, en una extensión de cerca 128.000 km².

El área de afloramiento del SAG se caracteriza principalmente como una zona de recarga directa del acuífero, donde tiene lugar la infiltración de parte de las aguas pluviales. Esto ocurre especialmente en las regiones planas, tales como planicies, plataformas estructurales de relieve suave, colinas. En el área de afloramiento del SAG existe interacción entre las aguas subterráneas y las aguas superficiales, como a lo largo de las vías fluviales de esta región de descarga de agua subterránea que constituye el nivel de base de los ríos y otros cuerpos de agua perenne. La evaluación de las reservas o el volumen de agua subterránea acumulada y móvil en el acuífero en el decurso de un determinado período de tiempo puede estimarse a partir de los estudios en la disponibilidad de agua, que se refiere al potencial explotable de un acuífero, es decir, la cantidad de agua disponible para su uso y que puede ser obtenida a través de los pozos sin comprometer el equilibrio cuantitativo de las fuentes ${ }^{15}$.

Más de cien municipios utilizan las aguas del SAG para el abastecimiento público a través de pozos de extracción de agua subterránea ubicados tanto en la zona de afloramiento como en area confinada, destacando las siguientes ciudades, entre otras: Ribeirão Preto (100\%); Araraquara (50\%); São Carlos (50\%); y São José do Rio Preto (40\%). La parte restringida del SAG está más protegida de posibles actividades

14 ORGANIZACIÓN DE LOS ESTADOS AMERICANOS (OEA), Aquifero Guarani: programa estratégico de ação. Acuifero Guaraní: programa estratégico de acción, OEA, Brasil, Argentina, Paraguay, Uruguay, 2009, p. 23.

${ }^{15}$ ORGANIZACIÓN DE LOS ESTADOS AMERICANOS (OEA), Aquifero..., cit., p. 27. 
contaminantes debido a la cobertura de las rocas basálticas. Además, el área de afloramiento constituye la parte de entrada más vulnerable a posibles contaminantes. En ese sentido, con el fin de proteger el sistema en su conjunto, es una prioridad la planificación territorial en esta zona ${ }^{16}$.

La contaminación también puede ocurrir en las zonas de afloramiento y en sus proximidades (zonas de basalto fracturado, con la posibilidad de contaminación proveniente de la superficie), donde la vulnerabilidad es a menudo mayor. Por otro lado, En estos casos, también se observaron vulnerabilidades significativas. En locales cerrados, la vulnerabilidad es insignificante ${ }^{17}$.

La vulnerabilidad natural a la contaminación del SAG en São Paulo corresponde a áreas de formaciones de Botucatu y Piramboia, añadido a las zonas de depósitos aluviales, tras lo cual ellos se superponen capas poco espesas ${ }^{18}$.

Los autores hacen hincapié en que, en la identificación de la vulnerabilidad de la región realizada por el Instituto de Investigaciones Tecnológicas (IPT), el índice se situó en niveles generales medios a altos, y estas clases, a su vez, se subdividen en dos subniveles (alto y bajo), por lo que hay cuatro clases de vulnerabilidad, a saber: mediabaja, media-alta, alta-baja y alta-alta, como se ilustra en la figura 4.

\footnotetext{
${ }^{16}$ ALBUQUERQUE, José Luiz et ál., "Plano de desenvolvimento e proteção ambiental da área de afloramento do Sistema Aquífero Guarani no Estado de São Paulo: proposta preliminar", Actas del XVI CONGRESSO BRASILEIRO DE ÁGUAS SUBTERRÂNEAS, São Luís, 2010, p. 8.

${ }^{17}$ ORGANIZACIÓN DE LOS ESTADOS AMERICANOS (OEA), Aquifero..., cit., p. 19.

${ }^{18}$ ALBUQUERQUE, José Luiz (coord.), Subsídios ao Plano de Desenvolvimento e Proteção Ambiental da área de afloramento do Sistema Aquífero Guarani no Estado de São Paulo, IPT-CPLA, São Paulo, 2012, p. 10.
} 


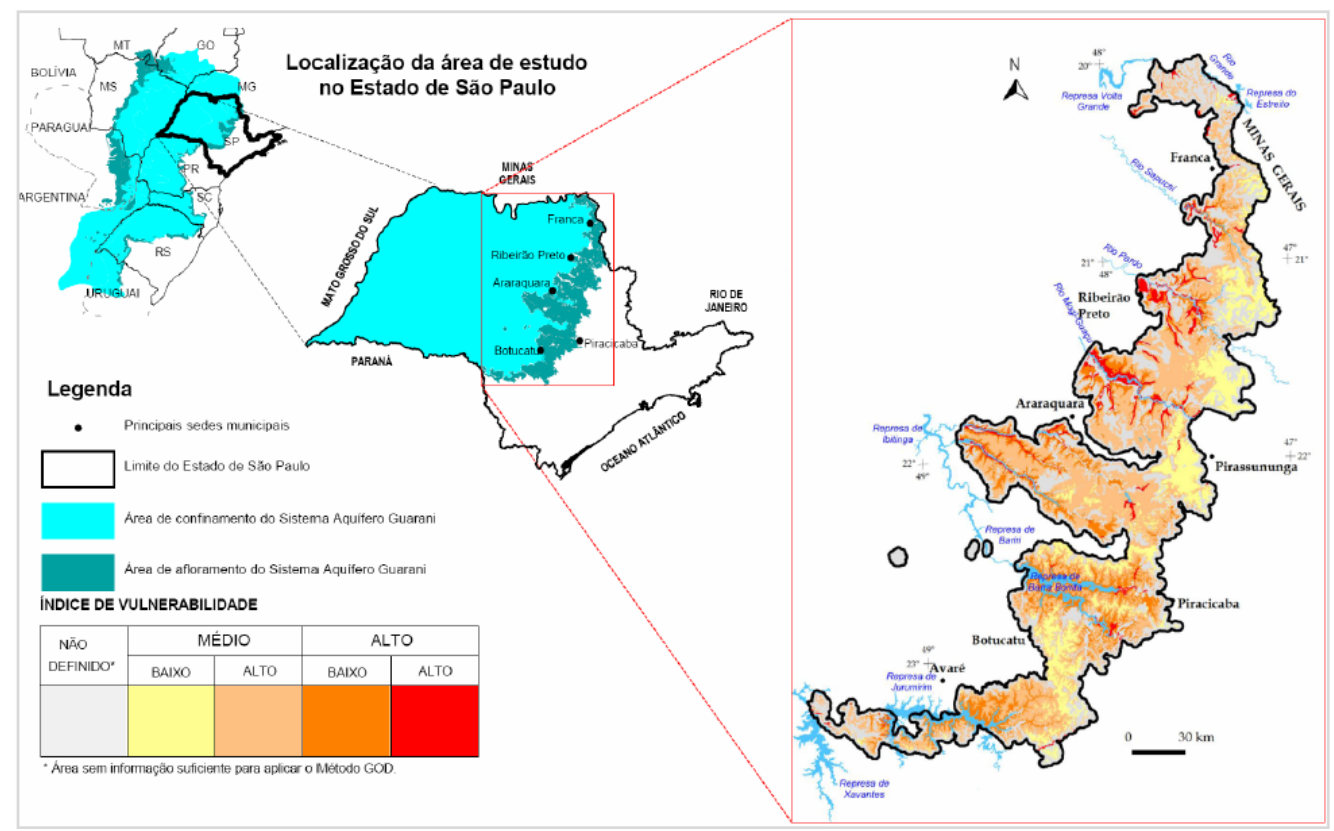

Figura 4. Vulnerabilidad natural a la contaminación en el área de afloramiento del SAG en el estado de São Paulo (Fuente: ALBUQUERQUE FILHO et ál.; 2012).

Hacemos hincapié en que los cambios en la calidad de las aguas subterráneas pueden ser causados directa o indirectamente por las diversas actividades humanas. Influencias directas son las derivadas de sustancias naturales o sintéticas que son introducidas por el hombre en el ciclo geoquímico y, en última instancia, llegan a las aguas subterráneas. Factores indirectos son los cambios en la calidad causados sin la interferencia del hombre, es decir, aquellos que se producen debido a los procesos biológicos naturales químicos, físicos y biológicos. Por lo tanto, cualquier modificación de origen antropogénico en la calidad de las aguas subterráneas del Sistema Acuífero se denomina polución, y, cuando esta modificación o degradación de la calidad natural del agua subterránea alcanza niveles que pueden afectar, de una manera perjudicial a la salud humana y de los animales que la consumen, se denomina contaminación ${ }^{19}$.

El uso y la ocupación del suelo afectan de forma distinta a la contaminación de las aguas subterráneas. La identificación del uso y la ocupación del suelo y la cuantificación de suyas ocupaciones demuestran el predominio de la ocupación antrópica en el área de afloramiento del SAG en el estado de São Paulo. Las áreas boscosas, a su vez, representan una parte importante de la zona de estudio; sin embargo,

19 COELHO, Virginia y DUARTE, Uriel, "Perímetros de proteção para fontes naturais de águas minerais”, Revista Águas Subterrâneas, num. 17, 2003, p. 78. 
hay que tener en cuenta que estas se concentran en la parte sur de la zona, que es una región más virgen. Puede ser considerada significativa el área dedicada al cultivo semiperenne, predominando el cultivo de caña de $\operatorname{azúcar}^{20}$.

Dado que en una importante área de afloramiento del SAG tienen lugar actividades de pastoreo y agrícolas, y que estas últimas utilizan grandes cantidades de pesticidas, deberían fomentarse mejores prácticas agrícolas, con el uso controlado de pesticidas, a fin de proteger el Acuífero. Es de destacar que las zonas urbanas de las ciudades más grandes del estado de São Paulo, como Piracicaba, Rio Claro, Araraquara, São Carlos, Ribeirão Preto y Franca, entre otras, no se encuentran o tienen solo una parte de su territorio en el área de afloramiento del SAG. Esto reduce al mínimo la contaminación difusa que podría acarrear la ausencia de sistemas de eliminación de aguas residuales, debido al saneamiento in situ, y comporta, además, que un número significativo de empresas (fuentes puntuales) no se encuentren en la zona de afloramiento del SAG ${ }^{21}$.

Teniendo en cuenta dos estudios técnicos realizados en el área de afloramiento del SAG, la ciudad de Araraquara fue elegida como el área de estudio ya que el $50 \%$ de su suministro de agua proviene del Acuífero Guaraní, tiene una población de más de 200.000 habitantes y diversas actividades económicas y también presenta el riesgo inminente de contaminación de las aguas subterráneas, ya que una parte importante de la zona de afloramiento del Acuífero Guaraní se encuentra en su territorio, especialmente en el área rural del municipio.

Esta región ha recibido la atención de los técnicos y los legisladores. El citado estudio técnico del Instituto de Investigaciones Tecnológicas, al analizar toda el área de afloramiento del SAG, indicó un alto potencial de contaminación de las aguas subterráneas en Araraquara. En el ámbito legal, el municipio ha propuesto una especie de zonificación ambiental para una parte de esta área de su territorio, planificando el uso y ordenamiento del suelo.

Araraquara se encuentra dentro de esta área de afloramiento del SAG y es considerada una ciudad importante en la región central del estado de São Paulo. Situada a unos 270 kilómetros de la capital, se encuentra a $21^{\circ} 47^{\prime} 40^{\prime \prime} \mathrm{S}$ y $48^{\circ} 10^{\prime} 32^{\prime \prime} \mathrm{O}$, a una altitud de

\footnotetext{
${ }^{20}$ ALBUQUERQUE, José Luiz (coord.), Subsídios ao Plano de Desenvolvimento e Proteção Ambiental da área de afloramento do Sistema Aquifero Guarani no Estado de São Paulo, IPT-CPLA, São Paulo, 2012, p. 19.

${ }^{21}$ ALBUQUERQUE, José Luiz et ál., "Plano de...”, cit., p. 10.
} 
664 metros. En su territorio de 1.016,55 $\mathrm{km}^{2}$ habitan 204.934 personas $^{22}$. Tiene una economía diversificada y fuerte, con gran vocación hacia el turismo y una agricultura bastante importante, especialmente de cultivos de naranjas y caña de azúcar.

Araraquara es un importante centro de negocios y de paso de mercancías. Se encuentra a $80 \mathrm{~km}$ del Hidrovía Tietê-Paraná, un cruce ferrocarril-carretera, con la red ferroviaria del Ferroban y la carretera Washington Luiz. Destacan los sectores agrícolas (principalmente naranjas y caña de azúcar), sector de la química fina, bioquímico y alimentario $^{23}$. La principal actividad económica del municipio es la industria manufacturera, que representa el 32\% del Producto Nacional Bruto, seguida de la agricultura $(27 \%)$, los servicios $(26 \%)$ y el comercio $(20 \%)$. Es de destacar que la mayoría de las industrias están ubicadas en zona urbana consolidada del municipio ${ }^{24}$.

El municipio se inserta en la Cuenca Hidrográfica Tietê-Jacaré, Unidad de Gestión de los Recursos Hídricos 13 (UGRHI 13), que se compone de 34 municipios, de los cuales 16 se hallan totalmente dentro de su área y 18 tienen parte de su territorio en UGRHI adyacentes. El Plan de la Cuenca Tietê-Jacaré no presenta datos sobre la disponibilidad de agua subterránea para toda la cuenca, estimada en $10,58 \mathrm{~m}^{3} \mathrm{~s}-1^{25}$.

Para las aguas subterráneas no hay una división regional semejante de la cuenca, el SAG va más allá de la Cuenca Tietê-Jacaré, y dada la dimensión continental del Sistema Acuífero Guaraní, su estudio se realiza de manera regional, con la delimitación de las áreas de estudio.

\footnotetext{
${ }^{22}$ INSTITUTO BRASILEIRO DE GEOGRAFIA ESTATISTICA (IBGE). (2014, 10 de abril) Censo demográfico de 2010. Recuperado el 10 de abril de 2014, de $<$ http://www.ibge.gov.br/censo2010/dados_divulgados/index.php?uf=35>.

${ }^{23}$ INSTITUTO DE PESQUISA TECNOLÓGICA (IPT). (2011, 11 de enero) Relatório Zero, 2000. Recuperado el 11 de enero de 2011, de <http://www.sigrh.sp.gov.br/sigrh>.

${ }^{24}$ MINISTÉRIO DAS CIDADES. (2011, 11 de enero) Banco de Experiências de Planos Diretores Participativos. Recuperado el 11 de enero de 2011, de <http://www.cidades.gov.br/secretariasnacionais/programas-urbanos/programas/programa-de-fortalecimento-da-gestao-municipal-urbana/bancode-experiencias/sao-

paulo/araraquara/Participacao_Social_atraves_de_Conselho_Municipal_de_Politica_Urbana_Ambiental_ e_integracao_intersetorial_Araraquara_SP.pd $\overline{\mathrm{f}}$.

${ }^{25}$ INSTITUTO DE PESQUISA TECNOLÓGICA (IPT). (2011, 11 de enero) Relatório Zero, 2000. Recuperado el 11 de enero de 2011, de <http://www.sigrh.sp.gov.br/sigrh>.
} 


\section{PLAN DIRECTOR ARARAQUARA-SÃO PAULO}

\section{Anterior Plan Director de Araraquara}

La Ley Complementaria núm. 350, de 27 de diciembre de 2005, instituyó el Plan Director de Desarrollo Urbano y Política de Medio Ambiente de Araraquara, con 259 artículos. La gestión ambiental está presente en su sección III — “Estrategia de Desarrollo Urbano Ambiental”, subsección I, "Medio Ambiente y Recursos Hídricos"; en los artículos 49 a 57 se establecen los principios, objetivos y directrices de la política municipal para el medio ambiente, fijando las acciones estratégicas para el desarrollo de esta política; en los artículos 58, 59 y 60 a 62 se analiza la gestión del medio físico, la del medio biótico y la de los recursos hídricos y aguas superficiales y subterráneas, respectivamente.

Respecto a la gestión del saneamiento ambiental, los artículos 63 a 85 de la subsección II regulan la cuestión de conformidad con la Ley de Política Nacional de Saneamiento (Ley Federal núm. 11.445/07). En cuanto al uso de la tierra, el artículo 147 establece la macrozonificación territorial y el artículo 149 define en la sección III la zona rural como un área extensiva donde las directrices para el uso y la ocupación deben ante todo fomentar las actividades agroindustriales, agroecológicas y de turismo sostenible.

Dada la importancia de la zona rural para la ciudad, el artículo 174, III, crea la Zona de Producción Agrícola (ZOPAG), un área de predominio del sector primario y de ocupación extensiva de baja densidad, con la producción agroindustrial ubicada preferentemente en las zonas rurales. La producción agroecológica podrá autorizarse en zonas urbana y rural, clasificadas de la siguiente manera: a) ZOPAI - 1: Zona de Producción Agroindustrial; b) ZOPAS: Zona de Producción Agroecológica Sostenible. El SAG se encuentra en la zona rural de Araraquara.

\section{La Ley Complementaria 49/01}

La Ley Complementaria núm. 49, de 22 de diciembre de 2001, modificada por la Ley Complementaria núm. 350/05 y por la Ley Complementaria núm. 496/08, instituyó la denominada Zona de Protección del Acuífero Regional en el territorio del municipio, que se encuentra en el Área de Protección de Acuíferos Anhumas-Cabaceiras (APAQAnhumas), que cubre las Cuencas Hidrográficas de Ribeirões das Anhumas y de las Cabaceiras. La creación de la APAQ-Anhumas tiene por objetivo la conservación de la 
zona de recarga del Acuífero Guaraní en el territorio del municipio de Araraquara, asegurando la cantidad y el suministro permanente de agua de calidad para la población (artículo 1., , único.).

En su artículo $3 .^{\circ}$ enumera las directrices para el uso y la ocupación del suelo y establece las actividades prohibidas, las actividades de bajo control del Ayuntamiento, las actividades estimuladas por el Ayuntamiento y las actividades obligatorias, con disposiciones relativas a los casos de incumplimiento y las sanciones correspondientes.

Se puede decir que esta ley, al ofrecer protección a una parte del área de afloramiento del SAG en Araraquara, cumple la verdadera función constitucional del municipio de legislar el uso y ordenamiento del suelo y promover la protección del medio ambiente.

Esta ley representa la innovación que destacamos en este trabajo, pues, al instituir la Zona de Protección del Acuífero Regional en el municipio, lo hizo para proteger parte del área del afloramiento de SAG en su territorio o sea para proteger las aguas subterráneas del SAG. Asimismo, se trata de la primera ley municipal en Brasil que, mediante la integración de la protección del suelo, protege las aguas subterráneas.

Sin embargo, la ley del Plan Director que aseguraba eficacia a esta legislación fue revocada, y la ley actual del Plan Director está todavía en fase de reglamentación de diversos de sus instrumentos, por lo que la protección de la Zona de Protección del Acuífero Regional necesita nuevos estudios técnicos.

\section{Actual Plan Director de Araraquara-São Paulo}

El Plan Director de Araraquara fue cambiado recientemente. La Ley Complementaria núm. 850, de 11 de febrero de 2014, estableció la revisión del Plan Director para el Desarrollo y Política Ambiental de Araraquara con la revocación de la Ley Complementaria núm. 350/05 y sus modificaciones, e instituyó el Plan Director para el Desarrollo y Política Ambiental de Araraquara, como se establece en el $\S 3 .^{\circ}$ del artículo 40 del Estatuto de la Ciudad.

El nuevo Plan Director (Ley Complementaria núm. 850, de 11 de febrero de 2014) pasó a través de un proceso de intenso debate con la comunidad, incluyendo manifestaciones y protestas de los ambientalistas y urbanistas con respecto a los posibles usos del suelo en la area conocida como Zona de Protección del Acuífero Regional, importante area de 
recarga del SAG en el territorio del municipio, que solo puede ser mejor analizada después de estudios técnicos y jurídicos al fin de la regulación de sus dispositivos, pero es cierto que su área de protección fue disminuida.

La nueva Ley se compone de 212 artículos y adopta todos los instrumentos urbanos del Estatuto de la Ciudad, así como del medio ambiente, algunos de los cuales deben ser regulados. El actual Plan Director disciplina y ordena la parcelación, uso y ocupación del suelo en todo el municipio y los planes regionales con vistas al cumplimiento de su función social. Además, fija, para todas las propiedades, las normas para las condiciones físicas, ambientales y paisajísticas locales y sus relaciones con los elementos estructuradores e integradores de sitio, las condiciones de acceso y la infraestructura disponible, división, usos y volumetría compatibles y las condiciones de confort ambiental.

Respecto de la creación de la macrozonificación y la zonificación, estas incluirán una configuración de zonas y áreas especiales de urbanización de acuerdo con los conceptos y directrices que figuran en el artículo 122 del Plan Director. La zonificación urbana está definido y constituido por las clasificaciones de uso del suelo, especialmente para este estudio por los apartados del artículo 123, que se describe:

XII. Zona de Ocupación Controlada en APAQ (Área de Protección del Acuífero) Zona (Z5A) - zona mixta en el área de protección del acuífero;

XIII. Zona predominantemente residencial en APAQ (Área de Protección del Acuífero) (Z5B) - predominantemente zona residencial en el área de protección del acuífero;

XIV. Zona de Producción Económica en APAQ (Área de Protección del Acuífero) (Z5C) - área de producción económica en área de protección del acuífero;

XV. Zona de Protección Ambiental (Z5D) - área de protección ambiental en APAQ en la que serán admitidos usos y actividades de preservación, protección y conservación de los recursos naturales, y asentamientos sustentables para investigaciones, educación y gestión ambiental.

Todavía, el uso del suelo en esas Zonas necesitan de estudios técnicos para establecer las actividades que puedan llevarse a cabo en las zonas mencionadas, porque en los párrafos $4 .^{\circ}$ y $5 .^{\circ}$ de ese artículo hay previsión de que estudios y acciones deberán ser realizados para proteger las aguas subterráneas del SAG, considerando el aspecto 
geológico de esa área, y se señala que el Gobierno del municipio deberá contratar los estudios previstos.

Por otro lado, el artículo 136 fija las macrozonas de gestión ambiental que deberán contener las macrozonas de gestión urbana como unidades y entidades espaciales con fines de gestión de la información y seguimiento de la planificación ambiental y la política urbana ambiental.

Por último, destacamos que el actual Plan Director cuenta con mapas territoriales sobre los diversos temas tratados; sin embargo, afirmamos que el Plan Director actual necesita aún diversas reglamentaciones para su aplicación, principalmente para proteger las áreas de afloramiento del Sistema Acuífero Guaraní en el municipio.

\section{CONCLUSIONES}

Primera. La legislación ambiental brasileña tiene como objetivo garantizar la protección y preservación del medio ambiente y de los recursos naturales en la búsqueda de la calidad de vida para todos, conforme a la Constitución Federal. Esta establece competencias ambientales distintas para los entes federados - Unión, estados, Distrito Federal y municipios - , dándo a los estados la responsabilidad de legislar sobre aguas subterráneas y a los municipios el uso y la ordenación del suelo.

Segunda. Las aguas subterráneas se encuentran en el subsuelo y se acumulan entre las fracturas, las fisuras y los poros de las rocas. Los depósitos de agua subterránea que pueden ser explotados se llaman acuíferos. El Sistema Acuífero Guaraní (SAG) es un importante manantial subterráneo de Latino América que debe ser estudiado y que requiere el establecimiento de leyes que compatibilicen el uso y ordenamiento del suelo con la protección de las aguas subterráneas. No es posible disociar suelo y agua en la gestión del territorio municipal.

Tercera. La elección de la ciudad de Araraquara, São Paulo, se dio por ser pionera en legislar para proteger el área de afloramiento del Sistema Acuífero Guaraní. Sin embargo, con el nuevo Plan Director de la ciudad, dicha protección encuentra indefinición legal, una vez que necesita de estudios tecnicos y de reglamentación para mejor definir las actividades en el suelo de las Zonas de protección creadas para las areas del SAG en su territorio. 
Cuarta. Podemos afirmar que el suelo es la clave para proteger los acuíferos. La forma de ordenar la ocupación y el uso del suelo en el planeta asegurará el mantenimiento y el uso de las aguas subterráneas; en Brasil, siendo competencia de los municipios legislar el uso y ordenamiento del suelo, urge que los municipios que se sirven de las aguas de los acuíferos también legislen de forma integrada, buscando la protección y conservación de las aguas subterráneas.

\section{BIBLIOGRAFÍA}

ALBUQUERQUE FILHO, J. L., "Plano de desenvolvimento e proteção ambiental da área de afloramento do Sistema Aquífero Guarani no Estado de São Paulo: proposta preliminar", Actas del XVI CONGRESSO BRASILEIRO DE ÁGUAS SUBTERRÂNEAS, São Luís, 2010.

- (coord.), Subsídios ao Plano de Desenvolvimento e Proteção Ambiental da área de afloramento do Sistema Aquífero Guarani no Estado de São Paulo, IPT-CPLA, São Paulo, 2012.

ARARAQUARA. (2001, 22 de diciembre) Lei complementar n. 49/01. Recuperado el 20 de febrero 2014, de <http://www.camara-arq.sp.gov.br/Legislacao/default.aspx

- $\quad$ (2005, 27 de diciembre) Lei complementar n. 350/05. Recuperado el 20 de junio de 2013, de http://www.camara-arq.sp.gov.br/Legislacao/default.aspx

- $\quad$ (2008, 9 de octubre) Lei complementar n. 496/08. Recuperado el 20 de junio de 2013, de http://www.camara-arq.sp.gov.br/Legislacao/default.aspx

- $\quad$ (2014, 11 de febrero) Lei complementar n. 850/14. Recuperado el 20 de febrero de 2014, de http://www.camara-arq.sp.gov.br/pagina/Default.aspx?IDPagina=81

ASSINE, M. L., "Os paleodesertos Pirambóia e Botucatu”, Mantesso Neto, V., Bartorelli, A., Carneiro, C. D. R. y Brito-Neves, B. B. (orgs.), Geologia do Continente Sul-Americano: Evolução da obra de Fernando Flávio Marques de Almeida, Editora Beca, São Paulo, 2004.

BRASIL. Constituição da República Federativa do Brasil: Promulgada em 5 de outubro de 1998, Saraiva, São Paulo, 2014. 
- (1981, 31 de agosto) Lei n. 6983/81, Lei da Política Nacional de Meio Ambiente. Recuperado el 20 de febrero de 2014, de http://wwww.planalto.gov.br/ccivil_03/Leis/L6938.htm

- (1997, 8 de enero) Lei n. 9433/97, Lei da Política Nacional de Recursos Hídricos. Recuperado el 20 de febrero de 2015, de http://www.planalto.gov.br/ccivil_03/leis/19433.htm.

CETESB. (2014, 15 de mayo) Águas. Recuperado el 15 de abril de 2014, de http://www.cetesb.sp.gov.br/

COELHO, V. M. T. y DUARTE, U., "Perímetros de proteção para fontes naturais de águas minerais”, Revista Águas Subterrâneas, núm. 17, 2003.

FIORILlO, C. A. P., O Direito de Antena em face do Direito Ambiental no Brasil, Saraiva, São Paulo, 2000.

- Estatuto da Cidade Comentado. Lei 10.257/2001. Lei do Meio Ambiente Artificial, Saraiva, São Paulo, 2005.

GASTMANS, D., "Hidrogeologia e hidroquímica do Sistema Aquífero Guarani na porção ocidental da bacia sedimentar do Paraná”, tesis doctoral, UNESP, Rio Claro, 2007.

INSTITUTO BRASILEIRO DE GEOGRAFIA ESTATISTICA (IBGE). (2014, 10 de abril) Censo demográfico de 2010. Recuperado el 10 de abril de 2014, de http://www.ibge.gov.br/censo2010/dados_divulgados/index.php?uf=35

INSTITUTO DE PESQUISA TECNOLÓGICA (IPT). (2011, 11 de enero) Relatório Zero, 2000. Recuperado el 11 de enero de 2011, de http://www.sigrh.sp.gov.br/sigrh

MACHADO, P.A.L., Recursos Hídricos. Direito Brasileiro e Internacional, Malheiros Editores, São Paulo, 2002.

MINISTÉRIO DAS CIDADES. (2011, 11 de enero) Banco de Experiências de Planos Diretores Participativos. Recuperado el 11 de enero de 2011, de http://www.cidades.gov.br/secretarias-nacionais/programas-

urbanos/programas/programa-de-fortalecimento-da-gestao-municipal-urbana/banco-deexperiencias/sao-

paulo/araraquara/Participacao_Social_atraves_de_Conselho_Municipal_de_Politica_Ur bana_Ambiental_e_integracao_intersetorial_Araraquara_SP.pdf 
MINISTÉRIO DO MEIO AMBIENTE (MMA), Águas subterrâneas: programa de águas subterrâneas, Ministério do Meio Ambiente, Brasília, 2001.

ORGANIZACIÓN DE LOS ESTADOS AMERICANOS (OEA), Aquifero Guarani: programa estratégico de ação. Acuífero Guarani: programa estratégico de acción, OEA, Brasil, Argentina, Paraguay, Uruguay, 2009.

ROCHA, G. A., "O grande manancial do Cone Sul”, Estudos Avançados, USP, vol. 11, núm. 30, 1997.

SILVA, J. A., Curso de direito constitucional positivo, Malheiros, São Paulo, 1999.

— Direito urbanístico brasileiro, Malheiros, São Paulo, 1992.

SILVA, R. B. G., Águas Subterrâneas: Um valioso recurso que requer proteção, DAEE, São Paulo, 2003.

SOUZA, L. C., Águas e sua proteção, Juruá, Curitiba, 2004.

— Águas subterrâneas e a Legislação brasileira, Juruá, Curitiba, 2009. 